\title{
Filtrokatadesmos: a simbiose entre os deuses gregos e egípcios nos períodos clássico e helenístico
}

\author{
'Filterkatadesmos': symbiosis between the Greek and Egyptian \\ gods in the Classical and Hellenistic periods
}

\author{
Maria Regina Candido*
}

Resumo: A marca de identificação sobre a prática mágica dos katadesmoi, que resultou na elaboração de filtros katadesmoi entre os atenienses, detém vestígios de sua prática durante a praga que afetou Atenas no meio da Guerra do Peloponeso. A magia dos katadesmoi tem a peculiaridade da evocação de diferentes divindades que controlam o espaço sagrado do submundo, chamados deuses ctônicos como Hades, Hermes, Perséfone, Cérbero, Caronte e Hécate. Eles estão presentes nas evocações dos filtros katadesmoi. A singularidade identificada no ritual do filtrokatadesmos é o surgimento de divindades gregas interagindo com os deuses egípcios, evocadas através das palavras mágicas escritas na superfície da lâmina de chumbo.

Abstract: The mark of identification about the katadesmoi magic practice that resulted in the elaboration of katadesmoi filters among the Athenians holds traces of their practice during the plague that affected Athens in the middle of the Peloponnesian War. The magic of the katadesmoi has the peculiarity of evoking different deities who control the underworld's sacred space, called Chthonian gods as Hades, Hermes, Persephone, Cerbero, Charon, and Hecate. They are present in the evocations of the katadesmos filters. The singularity identified in the ritual of the filterkatadesmoi is the emergence of Greek deities interacting with the Egyptian gods, evoked through the spells written in the surface of the lead blades.

\author{
Palavras-chave: \\ Magia. \\ Filtrokatadesmos. \\ Ritual. \\ Deidades. \\ Defixiones.
}

\section{Keywords:}

Magic.

Filterkatadesmos.

Ritual.

Deities.

Defixiones.

\footnotetext{
* Professora Associada da Universidade do Estado do Rio de Janeiro (UERJ), coordenadora do Núcleo de Estudos da Antiguidade (NEA/UERJ) e do PPGH/UERJ no biênio 2019-2021. Bolsista produtividade 2 do CNPq.
} 


\section{Introdução}

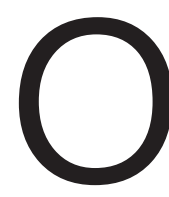

termo filtrokatadesmos significa um conjunto de atividades mágicas visando à realização do encantamento amoroso colocado em lâminas de chumbo. ${ }^{1}$ As fórmulas mágicas detêm a peculiaridade do uso de verbos no imperativo, como imobilizar, calar, paralisar, deter e, por vezes, deixam transparecer o verbo matar, que tem por fim fazer mal a alguém. Christopher Faraone (1999, p. 17) afima que a magia amorosa faz parte do refinado mundo de riqueza das hetairas e cortesãs que circulavam entre a elite das sociedades grega e romana. A afirmação do autor nos indica serem mulheres as protagonistas das práticas dos filtros mágicos no Mundo Antigo. Madeleine Jost (1992, p. 277) afirma que a prática da magia seria um atributo específico das mulheres devido ao seu lugar de fala marginal na pólis, e estariam inclinadas à prática da magia dos filtrokatadesmoi. Acreditamos que o suporte para essa afirmação pertence à documentação proveniente da poesia épica, clássica e helenística. A literatura grega coloca as mulheres míticas, como Circe, Calipso, Medeia e Samanta como especialistas em raízes, detentoras do saber de manipulação das ervas como veneno/pharmakon allo ou remédio/pharmakon olomenon, ambos definidos pelo termo pharmakos, sendo as mulheres identificadas como pharmakides (CANDIDO, 2014, p. 154-170).

Neste artigo, nos propomos a analisar o ritual de realização do filtrokatadesmos, que detém a peculiaridade do envolvimento de divindades gregas interagindo com os deuses egípcios, evocados através da grafia presente na superfície da lâmina de chumbo. O que nos chama a atenção nesta magia amorosa é o fato de o solicitante pertencer ao sexo masculino e de reproduzir as fórmulas mágicas dos katadesmoi que circulavam pelo Mediterrâneo antigo.

O tema sobre a magia amorosa e os katadesmoi, que têm por finalidade fazer mal ao inimigo, possui uma acentuada historiografia nos campos da Arqueologia e da Filologia. ${ }^{2}$ Entretanto, nas últimas décadas, verifica-se uma escassez de publicações,

\footnotetext{
${ }^{1} \mathrm{Na}$ historiografia anglo-americana, denomina-se a lâmina de chumbo como Curse tablets, proveniente da cultura material desde a Antiguidade a partir dos seguintes pesquisadores: R. Wünsch, Defixionum Tabellae Atticae (1897); A. M. H. Audollent, Defixionum Tabellae (1904); H. Solin, Eine Neue Fluchtafel aus Ostia (1968); D. R. Jordan, A survey of Greek defixiones not included in the special corpora (1985); D. R. Jordan, New Greek curse tablets (1985-2000) (2000); A. Kropp, Defixiones: ein aktuelles corpus lateinischer Fluchtafeln (2008).

${ }^{2}$ Indicamos as publicações de Hans-Dieter Betz e a coleção The Greek Magical Papyri in Translation (1981); D. R. Jordan (1985), A Survey of Greek Defixiones Not Included in the Special Corpora; A. Bernand, com Sorcier Greecs (1991); Christopher Faraone e Dirk Obbink, com o livro Hiera Magika (1991); John Gager (1992), com o livro Curse Tablets and Binding Spells; Roy Kotansky (1994), com a coleção Greek Magical Amulets; Amor López Jimeno (2001), com o livro Textos griegos de maleficio; Daniel Ogden com Magic, Witchcraft and Ghost in the Greek and Roman world: $A$ source book (2002); Francisco Marco Simon e Richard L. Gordon (2010), com a publicação Magical practice in the Latin West; e Andrew T. Wilburn (2012), com o livro The Archaeology of Magic in Roman, Egypt, Cyprus, and Spain.
} 
eventos e congressos abordando as práticas mágicas dos katadesmoi no Mundo Antigo. O tema carece de espaço junto ao meio acadêmico da América Latina; caso o pesquisador faça um levantamento bibliográfico, deparar-se-á com acentuada escassez de produção sobre o tema. No entanto, devemos mencionar que a maneira de fazer a magia dos katadesmoi já circulava nas regiões banhadas pelos mares Mediterrâneo e Egeu, praticada principalmente pelos atenienses dos períodos clássico e helenístico.

Por que trazer o tema sobre as práticas mágicas gregas para o primeiro plano na atualidade? Podemos afirmar que o mundo atual se tornou muito mais plural quando observamos a diversidade de seitas, cultos e movimentos religiosos que geram conflitos e ratificam o não desencantamento do mundo. O termo desencantamento do mundo pertence a Max Weber, ${ }^{3}$ e na modernidade denominou-se como dessecularização por Peter Berger. ${ }^{4}$ De acordo com Antonio Flávio Pierucci (2005, p. 33), a expressão desencantamento do mundo tornou-se poética em francês (désénsorcelement du monde) e, em alemão, nos remete à sentença Entzauberung der Welt. Argumentamos que a chegada da modernidade ou pós-modernidade não marcou o processo gradual de desaparecimento do interesse pelas crenças e práticas mágico-religiosas e do contato com o divino como se previa no século XIX.

A questão nos traz à lembrança a análise tripartida realizada pelo antropólogo Sir James Frazer, no livro 0 ramo de ouro, no qual o autor estabeleceu a distinção entre magia, religião e ciência. De acordo com Versnel (1994, p. 178), o termo ciência foi definido como um conhecimento verificável através de experimentos; a palavra religião pertencia à categoria de saberes dogmáticos baseados na crença e na fé; e a magia era considerada a ciência bastarda por oferecer um conhecimento operacional que visava a atender aos anseios privados do homem através do controle da natureza.

Para Luck (1985, p. 10), a relação de tensão estabelecida entre religião e magia se deve ao fato de a prática da magia ser considerada um ritual mal-entendido, definido como superstição. O termo magia, sorcer, Zauber, epodes ou feitiço detém, como transliteração, a ideia de encantamento. Para os gregos, encantar alguém significava envolver pelo canto, pelo uso da palavra que seduz, pela musicalidade que fascina, pelo epoides presente na melodia de Orfeu, nas vozes das Musas, nos procedimentos mágicos de Medeia e de

\footnotetext{
${ }^{3}$ Os defensores da premissa seriam Karl Max, Max Weber e Émile Durkheim, que defendiam que o mundo estava diante da emergência do racionalismo ocidental generalizado e heterogêneo.

${ }^{4}$ O pesquisador Peter Berger (2001, p.10-17) retoma a tese na década de 1970. Porém, reconhece que foi um equívoco supor que vivemos em um mundo secularizado. O mundo, na atualidade, é tão ferozmente religioso quanto no tempo passado. Isso quer dizer que toda uma literatura escrita pelos historiadores e cientistas sociais, vagamente chamada de teoria da secularização, está essencialmente equivocada.
} 
Samanta, na realização das práticas da magia amorosa/filtrokatadesmos e dos katadesmoi /defixiones (CANDIDO, 2017a., p. 16-25).

Podemos afirmar que os atenienses transitavam entre a religião, a magia e a descrença nos deuses, como nos aponta a especulação sobre a existência dos deuses trazida por Eurípides, que mantém interface com o pensamento de Protágoras de Abdera. A narrativa expõe que os protagonistas não tinham como afirmar a existência dos deuses cultuados pela pólis e nem como definir a sua forma divina, tendo em vista os muitos obstáculos que os impediam, a saber: de um lado, estava a ausência de clareza no assunto, e do outro, estava a curta duração da vida humana (Eurípides, Hécuba, v. 728).

O mesmo questionamento sobre a existência dos deuses olímpicos esteve presente em Teodoro, integrante da hetaireia pró-macedônia que, no século IV a.C., repudiava os deuses da pólis, rejeitando a possibilidade de existência de qualquer divindade, além de afirmar ser lícito roubar, cometer adultério e profanar os cultos aos deuses (Diogenes Laertius, I, 99). O resultado das especulações foi a condenação da personagem à morte pela acusação de impiedade/asebea. No entanto, a premissa do sofista de Abdera nos remete ao questionamento atual e nos permite afirmar que o mundo nunca deixou de lado a religiosidade, as crenças no encantamento, na magia, fato que nos permite afirmar que o universo atual se tornou acentuadamente um lugar de muitos deuses e de muitas crenças.

Para nós, helenistas, tornou-se difícil estabelecer as fronteiras entre as práticas da magia, ações religiosas e a ideia de ciência junto ao universo dos gregos. Analisando a materialidade das ações de religiosidade dos gregos, fica evidente que o usuário da magia evocava os mesmos deuses do panteão grego, fazia uso dos ritos das póleis e transitava pelos espaços consagrados pela religião oficial políade. A observação nos leva a afirmar que a magia entre os gregos se tornou uma ação complementar à religião oficial políade. Os cultos e ritos voltados aos deuses da natureza objetivavam estabelecer a relação culto-benefício para a pólis. No campo da magia dos katadesmoi, a relação cultobenefício também se faz presente ao evocar a alma de um defunto visando a prejudicar alguém, ou seja, fazer mal ao inimigo.

Fustel de Coulanges (1988, p. 20), na obra A cidade antiga, cita que, entre os antigos, os mortos necessitavam de alimentos e bebidas e cabia a nós, os vivos, satisfazerIhes esta necessidade. A citação nos aponta que a sepultura era o espaço sagrado dos mortos, lugar de interdito, inviolável e protegido pelos deuses e cultuado pelos homens. Segundo Aristófanes (Ranae, v. 150), os gregos constroem o espaço sagrado dos mortos situado no mundo subterrâneo, considerado um lugar frio, turvo, úmido, repleto de tristeza e sofrimentos. As divindades que controlam esse espaço sagrado do universo 
subterrâneo denominam-se deuses ctônicos e são personificados por Hades, Hermes, Perséfone, Cérbero, Caronte e Hécate, todos presentes nas evocações (CANDIDO, 2015, p. 57-74). O marco inicial da identificação da prática da magia dos katadesmoi/defixiones entre os atenienses foi atestado em meados de 432-431 a.C., relacionado ao processo de acirramento da Guerra do Peloponeso e da peste que assolou Atenas; a prática se estende por todo o período helenístico, chegando até o século VI d.C.

\section{Atenas e os cultos estrangeiros}

Podemos afirmar que a prática da magia dos katadesmoi/defixiones transitou para além do Mar Mediterrâneo no período clássico, helenístico e romano, pois as escavações arqueológicas encontraram vestígios de sua prática na ágora e no bairro Cerameico, em Atenas; na região de Sagunto, na Península Ibérica; no templo da deusa Sulis, Minerva/ Aquae Sulis, na região de Bath; no santuário do deus Mercúrio, em Uley; na Bretanha, na região de Olbia, no Mar Negro e no Egito. ${ }^{5}$

Em Atenas, os rituais estrangeiros tinham como ponto de entrada a região do porto do Pireu, como nos aponta Platão, ao mencionar o ato de Sócrates descer em direção ao porto, ou seja, katabaino eis Peiraia, para participar do culto estrangeiro da deusa Bentis, introduzida em Atenas, em 429 a.C., pelos trácios (FOUCART, 1873, p. 131). Vejamos a citação:

Ontem fui ao Pireu com Gláucon, filho de Aríston, a fim de dirigir as minhas preces à deusa e, ao mesmo tempo, com o desejo de ver de que maneira celebravam a festa, pois era a primeira vez que a faziam. Ora, a procissão dos habitantes dessa terra pareceu-me linda: contudo, não me pareceu menos aprimorada a que os trácios montavam (Platão, Respublica, I, 327a).

As escavações arqueológicas apontam a presença da estela de mármore IG, $\|^{2}$ 337, que evidencia as solicitações dos mercadores citas, no século IV a.C, interessados na construção de um santuário dedicado a uma divindade estrangeira semelhante à deusa Afrodite Ourania. O solicitante menciona, na epigrafia, que deseja o mesmo tratamento que foi concedido aos egípcios para a construção de um santuário à deusa Ísis na região do Pireu (GARLAND, 1987, p. 337).

Entre os cultos estrangeiros sediados no porto ateniense, havia magos e mulheres estrangeiras que executavam ritos de purificação, cultos apotropaicos e rituais de evocação

\footnotetext{
${ }^{5}$ Para maiores informações sobre a localização dos katadesmoi, ver o capítulo 'Catalogue of Binding Curses' do livro Oracles, Curses, and Risk among the Ancient Greeks, de Esther Eidinow (2007). Ver também o artigo de D. R. Jordan (1985), A Survey of Greek Defixiones Not Included in the Special Corpora.
} 
aos mortos visando a atender à solicitação dos vivos. Os magos e pharmakides, por uma expressiva quantia pecuniária, realizavam práticas de magia que tinham por finalidade prejudicar os inimigos ou adversários através da maneira de fazer dos katadesmoi/ defixiones e dos filtrokatadesmoi.

Anna Marie Ozanan (2012, p. x) considera que os praticantes e usuários da magia dos katadesmoi seriam pessoas simples, anônimas, escravos e principalmente prostitutas que circulavam livremente nos espaços físicos fora dos muros da pólis, como os cemitérios. Prontificamo-nos a trazer um olhar alternativo à afirmativa da autora para identificar quem seriam esses magos e feiticeiros. Recorremos aos oradores áticos, como Demóstenes, que sentenciou à morte a pharmakides Ninos, que atuava como sacerdotisa do deus Sabázio, assim como Threoris de Lemnos, acusada de prática de filtrokatadesmos, na obra Against Aristogeiton (I, 79). Andocides, no discurso Contra a Madrasta, e o orador Hipérides, que defendeu a amante Frineia de Thespis (Hyperides, 20). Os oradores áticos deixam transparecer os nomes das mulheres estrangeiras acusadas nos processos de impiedade impetrados no tribunal de Atenas. As mulheres estrangeiras foram acusadas de atuarem como pharmakides/feiticeiras, especialistas na elaboração de filtros mágicos/ filtrokatadesmoi, assim como das práticas da magia dos katadesmoi/ defixiones. Na obra Memoráveis (III, 11, 16-17), de Xenofonte, encontramos a musa e modelo do escultor Praxíteles, a jovem Teodota, que dialoga com Sócrates sobre filtros/ filtrokatadesmoi, encantamentos/epoidiai e magias/iunx/katadesmoi. Sócrates menciona que consegue manter a atenção de seus seguidores através de "uma quantidade de filtros, encantamentos e magia.". Temos, por suposição, que os acusadores das mulheres, responsáveis por dar início ao processo de prática da magia dos katadesmoi/defixiones, eram, por vezes, ex-amantes não conformados com o abandono ou algum cliente que havia se sentido prejudicado por ter ingerido alguma poção mágica afrodisíaca adicionada ao vinho ou por ter tido contato com algum unguento colocado na genitália feminina, cuja ação resultou em impotência sexual.

Outra peculiaridade encontrada nas lâminas de chumbo do século IV a.C. provém da evocação dos deuses ctônicos gregos nomeados junto com as divindades egípcias. Heródoto (Historiae, II, 50) afirma que a Hélade/Grécia recebeu do Egito diversas tradições religiosas. Para o "Pai da História", quase todos os nomes dos deuses gregos, incluindo as práticas da magia, eram de matriz estrangeira. Entretanto, verificamos que os nomes das divindades egípcias estavam ausentes nos katadesmoi de períodos anteriores ao século IV a.C. Após essa data, torna-se evidente a frequência dos nomes de Hermes, Hades, 
Perséfone, Cérbero e Hécate associados às divindades egípcias Anúbis (deus dos mortos), Seth (deus da desordem e da violência) e Thot, equivalente ao deus Hermes. ${ }^{6}$

A presença dos nomes de deuses egípcios nas lâminas ratifica que os profissionais da magia eram homens e/ou mulheres que viviam em transumância. Seres errantes, eram magos, feiticeiros e pharmakides itinerantes que transitavam pelas regiões do Mediterrâneo, do Egeu e Mar Negro, oferecendo os seus serviços por um alto preço e evocando os deuses locais por onde passavam, seguindo um repertório padrão. De acordo com André Bernand (1991, p. 132), a magia grega que tinha por objetivo fazer mal ao inimigo havia sido resultado da interação cultural com os egípcios. Consideramos que Heródoto, ao traçar o itinerário da magia grega a partir da região do Egito, deixa transparecer que os katadesmoi, a magia que visava a fazer mal aos inimigos, formavam um conjunto específico de saberes cuja prática situava-se fora da paideia grega.

Clemente de Alexandria expressa a opinião que já circulava no Mundo Antigo de que o Egito era o berço das práticas mágicas por deter um repertório de hinos, bibliotecas com livros sobre receitas mágicas e treinamentos de sacerdotes especializados em práticas mágicas. Geraldine Pinch (1994, p. 12) ressalta a simbiose que existia entre religião e magia junto à cultura egípcia, como expressam os termos heka e akhu, ambas palavras evocadas no sentido de encantamento, feitiçaria e magia. A autora acrescenta que o sacerdote egípcio, em geral, usava a magia para atingir fins privados.

\section{Filtrokatadesmos: um estudo de caso}

Como estudo de caso, trazemos o conjunto de artefatos relacionados à magia egípcia que envolve a evocação de deuses gregos, os artefatos identificados pelo inventário E27145, localizado no Museu do Louvre, Paris. Os artefatos são provenientes da região de Antinópolis, situada às margens do Rio Nilo, próximo da cidade de AlMinya. O conjunto é composto por uma estatueta que representa uma figura feminina feita de argila, ajoelhada, transpassada por treze pregos. As peças foram encontradas junto a uma fina lâmina de chumbo/katadesmos que estava enrolada, em cuja superfície havia um texto que deixa transparecer o desejo do solicitante. Os dois objetos, a figura de argila e a lâmina de chumbo, estavam acomodados no interior de um vaso de barro e a historiografia tende a defini-los como filtrokatadesmoi, ou seja, materialidades da prática da magia amorosa. O objeto de análise pertence à cultura material e foi tema de

\footnotetext{
${ }^{6}$ Amanda Hutflesz, mestranda do Programa de Pós-Graduação em História Comparada da UFRJ, executa, sob nossa orientação, projeto de pesquisa sobre o assunto. O título provisório de sua dissertação é Interação cultural entre deuses gregos e egipcios nas práticas mágicas dos séculos $V$ e IV a.C.
} 
abordagem na academia francesa através de Bourguet, no artigo Ensemble magique de la période romaine en Egypt (1975), e de Sophie Kambisis, no artigo Une nouvelle tablette magique d'Égypte (1976). A análise do conteúdo do texto revela as mesmas características das lâminas de imprecação/curse tablets/katadesmoi presentes no catálogo The Greek Magical Papyri in Translation (1981), de Hans-Dieter Betz. A especificidade dessa prática mágica consiste em grafar o nome do desafeto, seguido de palavras de maldição, na superfície de pequenas lâminas de chumbo destinadas a serem enterradas em cemitérios, em leito de rios ou em fendas de santuários de deuses que detêm relação com o mundo dos mortos. A especificidade dos filtros amorosos/filtrokatadesmoi se deve ao fato de o solicitante e usuário da magia dos katadesmoi fazer uso de verbos de ação conjugados no modo imperativo, como "eu quero", "eu exijo", impressos nas lâminas de chumbo, associados a pequenas figuras humanas feitas de chumbo, enroladas em fios de cabelo, fragmentos de unhas, pedaços de roupa do ser amado e depositadas junto à mão direita dos considerados mortos antes do tempo, como as crianças/aoroi e vítimas de morte violenta, como os suicidas e pessoas assassinadas/biathanatoi.

De modo geral, as lâminas de imprecação, como os katadesmoi, deixam transparecer somente o nome das vítimas, porém, na imprecação amorosa/ filtrokatadesmos de nossa análise, podemos identificar o nome do solicitante, no caso, Sarapammon, filho de Area. O rapaz apaixonado, de nome Sarapammon, deseja ardentemente o amor da jovem Ptolomais, filha de Aias e de Orígenes. Percebe-se que, na prática da magia, o reforço da identificação dos envolvidos requer a presença do matromínico como fator de identificação, ou seja, provém da origem materna. A ação aponta a possível interação dos egípcios com o universo cultural dos helenos. Entre os atenienses, Aristóteles deixa transparecer, na obra Política (III, 1276 ${ }^{\mathrm{a}}$ ), o fator de identificação de um cidadão ateniense ao citar que "a cidadania é limitada só a filho de cidadãos pelo lado do pai e pelo lado da mãe, e não por um só lado". Entretanto, em periodos anteriores ao de Aristóteles, em 451 a.C., a filiação e a posse da cidadania ocorriam por meio do nome do pai/patronímico, ratificado pelo nome registrado no demos. No espaço das lâminas de chumbo, percebemos que, nas práticas da magia, tornara-se primordial a identificação do indivíduo através da filiação materna, o matronímico.

Em retorno ao tema, a elaboração da lâmina de chumbo nos permite afirmar que Sarapammon atuou sob a orientação de um profissional do rito/magos e de uma pharmakides. Os profissionais do rito evocaram o espírito de um ser morto, de nome Antinoo, para atuar como assistente de Sarapammon com o objetivo de realizar as 
práticas mágicas. ${ }^{7}$ A ação deixa transparecer que o jovem apaixonado estaria diante da sepultura do defunto Antinoo, que morreu jovem, ou seja, morreu antes do tempo, configurando-se como vítima ideal para ser manipulada em seu auxílio, visando à dinâmica no processo mágico. O jovem apaixonado evoca também a assistência de outros seres sobrenaturais, no caso, as divindades que transitam pelo mundo subterrâneo, como os deuses ctônicos Plutão/Hades, Coré/Perséfone/Ereschigal, Adônis, Hermes/Thot e Anúbis. Sarapammon evoca os deuses gregos associados às divindades egípcias. Tal fato indica o saber-fazer de profissionais do rito que transitavam pela região greco-romana, formando uma sociedade híbrida e multicultural. Para complementar a ação mágica dos filtrokatadesmoi, o protagonista evoca os espíritos das crianças que morreram antes do tempo/aoroi (linhas 1-6).

Sarapammon exige que o defunto Antinoo, seu assistente, levante-se da sepultura e parta em busca de sua amada, Ptolemais, e que desperte na jovem amada o sentimento de uma forte paixão pelo protagonista da ação, de forma que ela não consiga comer, beber, dormir e que, inclusive, jamais tenha prazer sexual com outro homem (linhas 6-11). O solicitante apaixonado exige que os sentimentos e a atenção da jovem Ptolomais sejam direcionados somente para ele por toda a eternidade (linhas 23-27). Ao final do texto, Sarapammon cita: "Se você conseguir isso para mim, eu irei libertá-lo" (linhas 27-28), ou seja, o protagonista ameaça não libertar a alma do defunto-assistente Antinoo até que seja realizada a conjunção amorosa de Sarapammon com a jovem Ptolomais.

O texto inscrito na superfície do katadesmos segue a fórmula das demais imprecações, a saber: um acentuado sentimento emocional do solicitante, seguido da indicação do nome da vítima, evocação de espíritos ctônicos e o uso de verbos de comando e ameaças, sempre no imperativo. Podemos observar que a diferença da imprecação amorosa/filtrokatadesmos das demais lâminas de maldição está no fato de o protagonista, envolvido na relação de amor, expressar o desejo de manter ou reaver a pessoa amada através do uso dos filtros amorosos. Nos casos de não atendimento e realização do objetivo de trazer a pessoa amada de volta ou a ausência de sucesso em chamar a sua atenção e despertar a sua adoração, emerge a exigência da destruição total da pessoa amada.

Dois fatores nos chamam a atenção nesta lâmina de chumbo encontrada no Egito com a imprecação amorosa: em primeiro lugar, as práticas da magia amorosa

\footnotetext{
${ }^{7}$ Consideramos que o protagonista realizou um ritual visando a adquirir poderes sobre um defunto para que atuasse como seu assistente. Segundo o rito, esse defunto assistente revelaria tudo o que o solicitante desejasse saber, e o morto seria um companheiro de todas as horas, do momento da refeição à base de leite, mel e vinho até na hora de dormir. Ver PGM I, 1-42.
} 
dos filtokatadesmoi integram a gestão de gênero. Em segundo lugar, existe uma fórmula padrão na confecção do filtrokatadesmos (figura humana e lâmina de chumbo) transpassada por pregos/passalos junto à evocação do morto vítima de morte singular. O tema sobre a magia erótica tem atraído os scholars devido à diferença de abordagem entre a documentação literária e a cultura material dos katadesmoi.

Determinados rituais de magia, que envolviam amiúde a produção de filtros amorosos e unguentos afrodisíacos, transitavam pelo universo feminino. Os rituais que exigiam a manipulação do corpo do morto, como a necromancia eram práticas exercidas exclusivamente pelas mulheres. Como exemplo, indicamos a acusação de Frinea de Thespis, amante do orador Hipérides. Os gregos consideram que as mulheres já traziam consigo o miasma proveniente da sua natureza feminina, como a menstruação, fato que qualifica as mulheres para exercerem determinadas práticas ritualísticas de contato direto com o corpo do morto. Por outro lado, somente os homens, após realizarem um ritual de purificação, estavam capacitados a evocar a alma de um defunto e a entrar em contato com o universo dos mortos através do ritual da katábasis e da psychagogos.

De acordo com Georg Luck (1985), os rituais de consulta aos mortos tinham muitas variações na Antiguidade. $\mathrm{O}$ autor ressalta que os rituais de consulta aos mortos eram conhecidos como rituais que se inseriam no campo da psychagogia, que significa o ato de evocação e contato com as almas dos mortos. A execução depende do psychagogos, especialista em evocar espíritos dos mortos para consultá-los sobre o devir; além disso, o ritual também era mencionado como necromancia. Entretanto, George Luck (1985, p. 12) ressalta que, embora tenha outros significados, o termo psychagogos torna-se o mais adequado e aplicado ao gênero masculino, cuja função era apenas obter informações sobre o devir. A documentação mais recuada sobre a evocação dos mortos pode ser encontrada em Homero (Odyssey, X, 480-510), ao narrar o ritual de psychagogos exercido pelo herói Odisseu, assim como a ação de Héracles no drama satírico Alcestes (Eur., Hec., v. 1125-1130), na evocação da alma do rei Dario na dramaturgia Persas (v. 680), de Ésquilo, e do pharmakeus Empédocles de Agacras (480-435 a.C), ${ }^{8}$ ao apresentar a sua capacidade de abrir o portão do Hades e estabelecer contato com a alma dos mortos e, em seguida, retornar ao mundo dos vivos sem o perigo de cometer a hybris ou trazer o miasma para a superfície (CANDIDO, 2006, p. 189-198).

${ }^{8}$ A descrição da prática ritualística de Empédocles de Agacras está presente em fragmentos da obra Purificações. 


\section{Magia e as fronteiras étnica e de gênero}

No universo das práticas mágicas de contato com os mortos, consideramos que havia a demarcação de fronteiras étnicas e de gênero. No entanto, temos dificuldade em afirmar serem as mulheres estrangeiras as únicas detentoras do saber-fazer relativo à magia dos katadesmoi ou defixiones, pois havia sacerdotes de cultos e ritos estrangeiros identificados como agyrtes, metragyrtes e menagyrtes, acusados pelos poetas e oradores áticos de cometerem fraudes, engodo e agirem como goetes no sentido pejorativo da palavra (FOUCART, 1873, p. 176). Os praticantes da magia colocavam à disposição dos

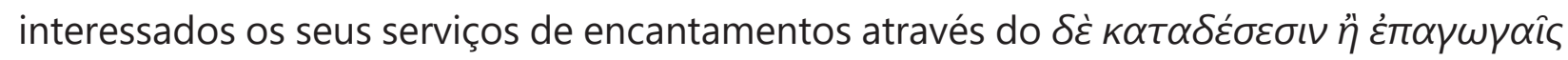

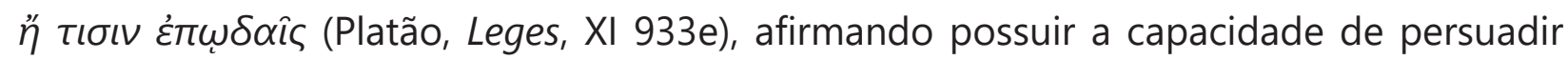
os seres sobrenaturais a atender às diferentes solicitações dos usuários da magia de prejudicar os inimigos.

Os magoi ofertavam o seu ofício às comunidades por onde passavam, cobrando assim um alto preço pelos serviços, e costumavam fazer a invocação das divindades ctônicas, nas regiões de passagem, produzindo com isso um repertório próprio e específico. Tanto Heráclito de Éfeso quanto Platão ratificam a presença desses magoi errantes em Atenas, atuando como profissionais dos ritos mágicos, com expertise na realização das práticas mágicas dos katadesmoi. Os magoi foram definidos como feiticeiros e goetes/charlatães por Heráclito, a saber: "[...] os errantes noturnos, os magos, as bacantes, as mênades, os mystai [...] e os sem piedade se iniciam nos mistérios em voga entre os homens" (Clemente de Alexandria, Protreptikos pros Ellenas, 22, 2). Platão considerava de má reputação aquelas pessoas que vagavam pela pólis anunciando a posse de um saber capaz de coagir os deuses a prejudicar os indivíduos considerados inimigos, trazendo-lhes a infelicidade e o prejuízo. Os errantes assumem o epíteto de mendigos e adivinhos itinerantes, que iam às portas das pessoas de recursos tentando convencê-las da capacidade de saberfazer feitiços e encantamentos, inclusive para prejudicar o inimigo. O filósofo acrescenta que, por uma quantia pecuniária, estes magoi/agyrtes divulgavam ter a capacidade de persuadir os deuses a serem seus servidores, praticando a magia de fazer mal ao inimigo (Pl., Resp., 364c-d).

Em relação ao gênero, no capítulo intitulado "The constraints of Eros", Winkler (1991) considera os homens como agentes ativos da magia amorosa/filtrokatadesmos, enquanto Fritz Graf (1994), na obra La magie dans l'Antiquité Gréco-Romaine, ratifica que os homens, mais intensamente, usavam da magia amorosa para assegurar para si o amor da mulher amada. Christopher Faraone (1991) considera que a magia amorosa era praticada tanto por homens quanto por mulheres (PACHOUMI, 2013, p. 294-325). 
Em nosso estudo de caso, a lâmina de chumbo analisada revela que o solicitante seria do sexo masculino e de nome Sarapammon. A questão de gênero se faz presente na realização do ritual, pois o protagonista, assim como Odisseu, evoca o espírito de um homem morto nomeado como Antinoo, e somente os homens poderiam realizar o ritual de evocação da alma dos mortos através da katábasis. Porém, a lâmina de chumbo, com as exigências amorosas, seria colocada na mão direita do defunto evocado, cuja ação somente teria sido realizada pelas mulheres/pharmakides.

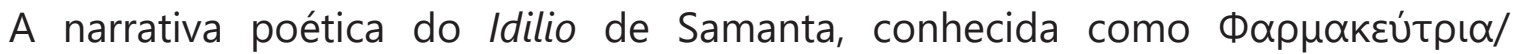
feiticeira, nos apresenta as etapas das ações mágicas para reaver ou ratificar uma relação de amor através dos procedimentos ritualísticos de confecção dos filtrokatadesmoi. Imaginamos que foram os mesmos passos seguidos por Sarapammon para conseguir o amor de Ptolomais. Samanta deixa transparecer que detém a expertise no saber-fazer os filtrokatadesmoi, ao mencionar "eu faço fundir esta cera com auxílio da deusa (Hécate) e assim despertar o amor de Delfos" (Teócrito, Idylls, II, v. 29), ou seja, a jovem apaixonada executa a magia amorosa acompanhada de uma figura de cera que representa o seu amado Delfos. Da mesma forma, Sarapammon reproduz, em chumbo, a figura de sua amada Ptolomais: uma figura feminina nua, com demarcação da genitália, com as mãos atadas às costas e de joelhos. Ambos parecem seguir a fórmula descrita no documento PGM IV 296-466. ${ }^{9}$ A fórmula nos fornece a receita de como despertar o amor e a fidelidade da pessoa amada, visando a reter somente para si a sua atenção e a satisfação sexual do ser amado.

Supomos, no entanto, que antes de realizar os procedimentos mágicos do filtrokatadesmos, Sarapammon teve de realizar um ritual de purificação. Para tanto, havia regras e preceitos seguindo a fórmula do documento PGM IV 2967-3006. O ritual fornece as indicações de como as ervas sagradas eram obtidas entre os egípcios, a saber: primeiramente, o solicitante purifica o próprio corpo, polvilhando-o com natrão junto com as ervas e resina de pinheiro. O solicitante deve, ao mesmo tempo, carregar uns galhos e folhas da erva sagrada e deve dar três voltas em torno do lugar. Em seguida, deve queimar kyphi (não sabemos o significado) e realizar a libação de orar aos deuses, derramando leite ao redor da planta e, ao término, retirar a raiz sagrada, sempre invocando o nome da divindade honrada.

\footnotetext{
${ }^{9}$ A figura de chumbo possui $9 \mathrm{~cm}$ de altura e encontra-se no Departamento de Antiguidades Egípcias do Museu do Louvre, marcada com o inventário E 27145. A sua apresentação ao público foi realizada por P. du Bourguet, em 1975, e em seguida foi analisada por Sophie Kambitsis (1976).
} 
O documento PGM IV 286-95 complementa o ritual de purificação ao especificar que todo o procedimento deve ser realizado antes do nascer do Sol e que o encantamento proferido deve seguir uma fórmula precisa de recitação, na qual o oficiante relata que está pegando a planta sagrada a fim de que ela possa ajudá-lo a alcançar o propósito, que é a aquisição do amor e da atenção da jovem Ptolomais (PGM IV 286-95). Após o ritual, segue a preparação da figura feminina, que representa a mulher amada e que deve ser preparada pelo jovem Sarapammon. A figura de chumbo tem a peculiaridade de ter o corpo perfurado por treze pequenas estacas ou pregos, de acordo com a fórmula a ser recitada durante o encantamento/epoides do filtrokatadesmos. Enquanto perfurava a figura de chumbo ou de cera, o jovem dizia:

Eu [Sarapammon] estou perfurando este prego no seu cérebro, [Ptolomais], enterro dois nos seus ouvidos, dois nos seus olhos e um na sua boca [...] dois em seu peito [...] um em sua mão, dois eu enterro na sua genitália e dois em seus pés. Eu enterro estes pregos, um em cada uma das partes do corpo de Ptolomais, para que você não se interesse por ninguém além de mim, viva somente para mim, só pense em mim (PGM, IV 296-446).

A fórmula nos traz à memória o ritual realizado por Samanta, que menciona: "três vezes eu faço esta libação e por três vezes eu pronuncio estas palavras, quem quer que se deite com ele, seja homem ou mulher, que ele esqueça completamente" (Theoc., Id., II, v. 45). A materialidade do encantamento revelado pela figura de cera perfurada segue o mesmo padrão descrito no documento PGM IV 296-446. A ação descrita se assemelha à de Samanta, que nos confirma que o ritual era um filtrokatadesmos, ao citar: "eu faço fundir esta cera (representando Delfos) com auxílio da deusa e assim despertar o amor de Delfos" (Theoc., Id., II, v. 30). Acreditamos que Sarapammon confeccionou a figura de chumbo representando a sua amada Ptolomais e, recorrendo ao encantamento e à musicalidade, ratificou o seu ardente desejo através da materialidade da grafia expressa pela escrita sobre a fina lâmina de chumbo/katadesmos.

$\mathrm{Na}$ etapa seguinte de preparação do filtrokatadesmos, podemos afirmar que a fórmula seguiu o padrão, como se observa na realização do encantamento amoroso contido no PGM VII 51, que diz: "havendo purificado o seu corpo durante todo o dia, evoque a senhora deusa Actiofi, Eresquigal Perséfone para que ela traga a sua amada Ptolomais, que ela arda de amor e que se cumpram os desejos noturnos, ABRASAX, rápido, rápido!" A lâmina deve ser acompanhada da figura de chumbo enrolada com fios de cabelos, fragmentos de unha e de vestuário da pessoa amada, recitando: "ABRASAX, 
eu envolvo Ptolomais rápido". ${ }^{10} \mathrm{Na}$ etapa seguinte, em geral, coloca-se o conjunto mágico no interior de uma sepultura de alguém vítima de morte violenta/biaios ou de um prematuro/aoros ou de um suicida. No caso de Sarapammon, os artefatos mágicos foram colocados dentro de um vaso de cerâmica, provavelmente alocado em algum cemitério na região às margens do Nilo.

\section{Conclusão}

Concluímos este estudo de caso afirmando que havia uma simbiose na elaboração dos filtros amorosos entre os deuses gregos e egípcios, como indica o conjunto de fórmulas dos documentos PGM. Essa constatação nos revela que a magia dos katadesmoi, tão criticada por Platão nas obras Leis e República, ratifica a existência de grupos de profissionais da magia que envolviam homens e mulheres que circulavam pelas regiões do Mediterrâneo, Egeu e Negro, oferecendo a sua expertise na elaboração do filttokatadesmos. Os solicitantes, independentemente do sexo, eram integrantes de um segmento social de recursos, pois o alto preço cobrado se deve aos riscos na realização da magia dos katadesmoi, que eram acentuadamente elevados. Caso a prática da magia fosse alvo de flagrante, constituiria um delito greve, cuja pena capital deveria ser imposta tanto ao solicitante quanto ao profissional da magia. Podemos afirmar que, ao final do período clássico e no início do helenístico, já estava em curso a dinâmica da conectividade marítima que resultou na ideia do interculturalismo, ${ }^{11}$ uma intensa simbiose étnico-cultural e religiosa, na qual as práticas mágicas também começaram a fazer parte do cotidiano de gregos e não gregos que interagiam de maneira sociocultural nas regiões banhadas pelos mares Egeu, Mediterrâneo e Negro (FARAONE, 2010).

\section{Referências}

\section{Documentação textual}

ARISTÓFANES. Rãs. Tradução de Maria de Fatima Silva. São Paulo: Annablume, 2014. ARISTOTLE. Politica. Translated by W. D. Ross. Oxford: Clarendon Press, 1957. AUDOLLENT, A. M. H. Defixionum Tabellae. Paris: Fontemoing, 1904.

\footnotetext{
10 Tradução e intrepretação da autora.

${ }^{11}$ Ver Cantle (2016).
} 
BETZ, H. D. The Greek Magical Papyri in Translation. Chicago: The University of Chicago Press, 1981.

CLEMENT OF ALEXANDRIA. The Exhortation to the Greeks. Translation by G. W. Butterworth. Cambridge: Harvard University Press, 1982.

DEMOSTHENES. Orations: 21-26. Cambridge: Harvard University Press, 1935.

DIOGENES LAERTIUS. Lives of Eminent Philosophers. London: William Heinemann, 1915.

ÉSQUILO. Os persas. Tradução de Trajano Vieira. São Paulo: Perspectiva, 2019.

EURÍPIDES. Hecuba. Madrid: Gredos, 1985.

GAGER, J. Curse tablets and binding spells. Oxford: Oxford University Press, 1992.

HERÓDOTO. História. Brasília: UnB, 1988.

HOMERO. Odisseia. Tradução de Carlos Alberto Nunes. Rio de Janeiro: Ediouro, 2000.

HYPERIDES. Minor Attic Orators. London: Harvard University Press, 1962. v. 2.

JIMENO, A. L. Textos griegos de maleficio. Madrid: Akal, 2001.

JORDAN, D. R. A survey of Greek defixiones not included in the special corpora. Greek, Roman and Byzantine Studies, v. 26, 1985.

JORDAN, D. R. Defixiones from a well near the Southwest corner of the Athenian Agora. Hesperia, n. 54, v. 3, p. 33-36, 1985.

JORDAN, D. R. New Greek curse tablets (1985-2000). Greek, Roman and Byzantine Studies, n. 41, 2000.

KAMBITSIS, S. Une nouvelle tablette magique d'Égypte. Musée du Louvre, inv. E 27145, n. 76, p. 213-223, 1976.

PLATÃO. Leis e República. Lisboa: Caloustre Gulbekian, 1993.

TEÓCRITO. Magia Erótica e Arte Poética, Idílio II. Tradução de Claudia R. Cravo. Coimbra: Universidade de Coimbra, 2008.

WÜNSCH, R. Defixionum Tabellae Atticae. Berlin: G. Reimer, 1897.

XENOFONTE. Memoráveis. Tradução de Ana Elias Pinheiro. São Paulo: Annablume, 2009.

\section{Obras de apoio}

BERGER, P. A dessacralização do mundo: uma visão global. Rio de Janeiro: ISER, 2001.

BERNAND, A. Sorcier greecs. Paris: Fayard, 1991.

CANDIDO, M. R. A iniciação da mulher grega como sacerdotisa de Hécate a partir da imagem do vaso intitulado Retorno de Perséfone. In: AGUIRRE, V. H. M.; TROCONIS, A.; IRIGOYEN, M. P. (ed.). Mujeres en Grecia y Roma y su trascendencia: diosas, heroínas y esposas. Ciudade de Mexico: UNAM, 2015, p. 57-74. 
CANDIDO, M. R. As práticas da magia na Atenas Clássica e ao longo do Mar Mediterrâneo. In: BAKOS, M. M.; MATOS, J. S.; BALTHAZAR, G. S. (org.). Diálogos com o mundo faraônico. Porto Alegre: FURGS, 2010, p. 193-202.

CANDIDO, M. R. Atenas e a materialidade do ofício de aprendiz de feiticeiro. Romanitas, n. 9, p. 16-25, 2017a.

CANDIDO, M. R. Mulheres estrangeiras e as práticas da magia na Atenas do século IV a.C. In: FUNARI, P. P. A.; FEITOSA, L. C.; SILVA, G. J. (org.). Amor, desejo e poder na Antiguidade: relações de gênero e representações do feminino. São Paulo: Unifesp, 2014, p. 154-170.

CANDIDO, M. R. O saber mágico-filosófico de Empédocles de Agracas na Atenas Clássica. Phoinix, v. 12, p. 189-198, 2006.

CANDIDO, M. R. Os espaços sagrados da deusa Hécate Ctônia na Atenas Clássica. In: SILVA, G. V.; SILVA, E. C. M.; LIMA NETO, B. M. (org.). Espaços do sagrado na cidade antiga. Vitória: GM Editora, 2017b, p. 266-278.

CANTLE, T. Interculturalism versus multiculturalism. Ethnicities, v. 16, n. 03, p. 470-493, 2016.

COLLINS, D. Magic in the ancient Greek World. Singapure: Markono Print, 2008.

COULANGES, F. A cidade antiga. Lisboa: Clássica, 1988.

FARAONE, A. C.; OBBINK, D. (ed.). Magika Hiera. Oxford: Oxford University Press, 1991.

FARAONE, C. A. A Greek magical gemstone from the Black Sea: amulet or miniature handbook? Kernos, n. 23, 2010.

FARAONE, C. A. Ancient Greek love magic. Cambridge: Harvard University Press, 1999.

FARAONE, C. A. Handbooks and anthologies: the collection of Greek and Egyptian incantations in Late Hellenistic Egypt, Archiv für Religionsgeschichte 2, n. 2, 2000.

FARAONE, C. A. The agonistic context of early Greek binding spell. In: FARAONE, C. A.; OBBINK, D. (ed.). Magika hiera. Oxford: Oxford University Press, p. 3-32, 1991.

FOUCART, P. Des associations religieuses chez les Grecs. New York: Arno Press, 1873.

GARLAND, R. The pireus. London: Duckworth \& C.O., 1987.

GOW, A. S. F. Theocritus. Cambridge: Cambridge University Press, 1950.

GRAF. F. La magie dans l'Antiquité Gréco-Romaine. Paris: Les Belles Lettres, 1994.

JOST, M. Aspects de la vie religieuse in Gréce: debut du V siècle a la fin du II siècle av J.C. Paris: Sedes, 1992.

KOTANSKY, R. Greek magical amulets. Opladen: Westdeutscher Verlag, 1994.

KROPP, A. Defixiones: ein aktuelles corpus lateinischer Fluchtafeln. Speyer: Kartoffeldruck-

Verlag Kai Brodersen, 2008.

LUCK, G. Arcana mundi. Madrid: Gredos, 1985. 
OGDEN, D. Magic, witchcraft and ghost in the Greek and Roman World: A source book. Oxford: Oxford University Press, 2002.

OZANAM, A. M. Hocus pocus : I'école des sorciers en Gréce et a Rome. Paris: Les Belles Lettres, 2012.

PACHOUMI, E. The erotic and separation spells of the Magical Papyri and Defixiones. Greek, Roman, and Byzantine Studies, n. 53, p. 294-325, 2003.

PASCUAL, P. H. Metafora y magia em 'La Hechicera' de Teocrito. Ágora, Estudos Classicos em Debates, n. 19, p. 117-146, 2017.

PIERUCCI, A. F. O desencantamento do mundo. São Paulo: Editora 34, 2005.

PINCH, G. Magic in Ancient Egypt. California: California University Press, 1994.

SIMÓN, F. M. (ed.). Fraude, mentiras y engaños en el Mundo Antiguo. Barcelona: Edicions Universitat Barcelona, 2013.

SIMON, F. M.; GORDON, R. L. Magical practice in the Latin West. Zaragoza: University of Zaragoza, 2010.

SOLIN, H. Eine Neue Fluchtafel aus Ostia. Commenta tiones humanarum litterarum. Societas scientiarum Fennica, v. 42, n. 3, 1968.

VERSNEL, H. S. Inconsistencies in Greek and Roman religion. Transition and reversal in myth and ritual. Leiden: Brill, 1994

WILBURN, A. T. The Archaeology of magic in Roman, Egypt, Cyprus, and Spain. Ann Arbor: The University of Michigan Press, 2012.

WINKLER, J. J. The constraints of Eros. In: FARAONE, A. C.; OBBINK, D. (ed.). Magika Hiera. Oxford: Oxford University Press, 1991, p. 214-243. 